\title{
Kalçanın travmatik çıkıkları
}

\section{Traumatic dislocations of the hip}

\author{
Tolga Atay \\ Süleyman Demirel Üniversitesi Tıp Fakültesi, Ortopedi ve Travmatoloji Anabilim Dalı, Isparta
}

\begin{abstract}
Kalça travmatik çıkıkları, yüksek enerjili mekanizmalardan kaynaklanan nadir yaralanmalardır. Bu hastalardaki eşlik eden yaralanmaları atlamamak için dikkatli bir travma değerlendirmesi gerekir. Mümkün olan en iyi sonuçları elde etmek için altı saat içinde yapılan erken kapalı redüksiyon, açık redüksiyon ve en önemlisi yakın radyolojik takip önerilmektedir. Hastayı potansiyel sekel ile ilgili eğitmek ve osteonekroz ve travma sonrası artrit bulguları için takip etmek de önemlidir.
\end{abstract}

Anahtar sözcükler: kalça eklemi; çıkık; akut
Traumatic hip dislocations are rare injuries caused by high-energy mechanisms. Care must be taken to assess the trauma to avoid the accompanying injuries in these patients. Early closed reduction, open reduction and most importantly close radiological follow-up within 6 hours are recommended to obtain the best possible results. It is also important to train the patient about the potential sequela and follow up for osteonecrosis and post-traumatic arthritis findings.

Key words: hip joint; dislocation; acute

kalça ekleminin o anda abduksiyonda veya adduksiyonda olmasına göre de yaralanma tipi değişir. Adduksiyon sırasında kişi önden darbe aldığı takdirde saf kalça çıkığı oluşurken, abduksiyon sırasında darbe aldığında, femur başı asetabulum arka duvarına çarptığı için, kalçanın kırıklı çıkıkları görülür. Posterior kalça çıkıkıı bir hastanın pozisyonu tipik olup, kalça eklemi ve dizi fleksiyon$\mathrm{da}$, alt ekstremitesi adduksiyonda ve iç rotasyondadır. Dolayısıyla, çıkıklı taraf sağlam tarafa göre kısalmış gibi gözükür. Posteriora çıııklarda siyatik sinir yaralanması da sıktır (\%10-20). Sinirin en sık peroneal dalları hasar görür, hasarlanma asetabular kırık parçalar veya çıkığa bağlı oluşan baskıdan kaynaklanabilir. Tibial dallar nadiren etkilenir (Şekil 1). ${ }^{[2]}$

Posterior kalça çıkıklarında çoğunlukla Thompson ve Epstein sınıflaması kullanılmaktadır.

Tip I: Posterior duvarda küçük bir parça ile birlikte olan veya olmayan basit çıkık.

Tip II: Tek büyük posterior duvar parçası ile birlikte çıkık.

Tip III: Parçalı posterior duvar kırığı ile birlikte çıkık.

Tip IV: Asetabular çatının kırı̆̆ı ile birlikte çıkık.

Tip V: Femur başı kırı̆̆ı ile birlikte çıkık.

- Iletişim adresi: Prof. Dr. Tolga Atay, Süleyman Demirel Üniversitesi Tıp Fakültesi, Ortopedi ve Travmatoloji Anabilim Dalı, Isparta Tel: 0532 - 4400099 e-posta: ataytolga@gmail.com

- Geliștarihi: 9 Kasım 2018 Kabul tarihi: 9 Kasım 2018 


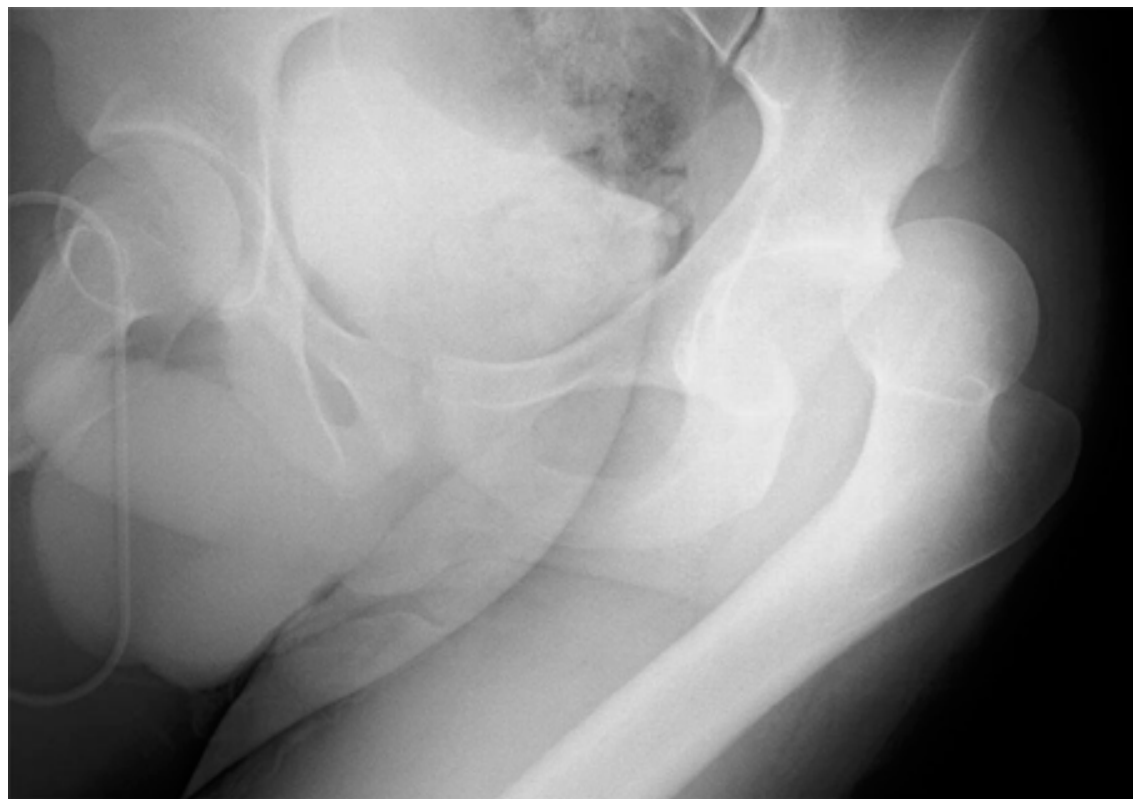

Şekil 1. On dokuz yaşında araç içi trafik kazası sonucu oluşan posterior kalça çıkığı.

İkinci sıklıkta görülen anterior kalça çıkıkları ise, kişi genelde ayakta kalça eklemi hafif abduksiyon ve dış rotasyonda iken kalça eklemine arkadan gelen bir darbe ile oluşur. Travma anında kalçanın fleksiyonu, anterior kalça çıkığının superior veya inferior tip olup olmamasını değiştirir. İnferior tip anterior kalça çıkığında, çıkık taraf abduksiyon, dış rotasyon ve fleksiyon pozisyonunda iken superior tipte abduksiyon, dış rotasyon ve ekstansiyondadır. Anterior kalça çıkığı her ne kadar daha az görülse de, çıkığa femur başı kırıklarının eşlik etme ihtimali daha yüksektir. Anterior çıkıklarda nadiren femoral arter ven veya sinir hasarı görülebilir.

Anterior kalça kırıklarında sıklıkla Epstein sınıflaması kullanılmaktadır.

Tip I: Pubik veya subspinozu içine alan superior çıkıklar.

IA: Femoroasetabular kırık yok.

IB: Kaput femoriste ezilme veya kırık.

IC: Asetabular kırık.

Tip II: Obturator ve perineali içine alan inferior çıkıklar.

IIA: Femoroasetabular kırık yok.

IIB: Kaput femoriste ezilme veya kırık.

IIC: Asetabular kırık.

En nadir görülen tip, santral kırıklı çıkıklar olup morbiditesi en kötü olan yaralanma tipidir. Genelde kişinin alt ekstremitesi nötral pozisyonda iken yana doğru düşme, yandan darbe alma veya göçük altında kalma sonucu görülür. Femur başı asetabulumu kırıp pelvis içine girdiğinden dolayı, çıkık taraf nötral pozisyonda ve kısalmış olarak gözükür. Asetabulum kırığından dolayı bu hastalarda hemorajik şok yönünden dikkatli olmak gerekir. Geç dönemde de kalça ekleminde osteoartrit görülme ihtimali yüksektir. ${ }^{[3,4]}$

Sonuçta; yukarıda bahsettiğimiz kalça çıkık tiplerinden hangisi olursa olsun, büyük çoğunluğu yüksek enerjili travma sonucu geliştikleri için tüm sistemik muayene sırasıyla yapılmalı, politravmalı hastaya yaklaşım basamakları uygulanmalıdır. Ayrıca, bu tür büyük eklem çıkıklarında, hastanın bilinci açıksa ağrı nedeniyle atlanan ek kırıklar görülebilir. Bu hastalarda redüksiyon öncesi ve sonrası dikkatli nörovasküler muayene yapılmalı ve kayıtlara geçirilmelidir.

\section{GÖRÜNTÜLEME}

Nasıl bir yaralanma ile gelirse gelsin, tüm hastalara acil serviste ön-arka pelvis grafileri rutin olarak çekilmelidir. Her ne kadar pelvis grafisinin uygun pozisyonda çekilmesi istense de, hem çıkık olan kalçanın pozisyonu hem de hastanın duyduğu ağrıdan dolayı, bazen bu mümkün olmayabilir. Anteroposterior grafide femur başının çıkık olan tarafta diğerine göre büyük olması anterior çıkığa işaret ederken, daha küçük görünmesi posterior çıkığa işaret edebilir. Lateral kalça 


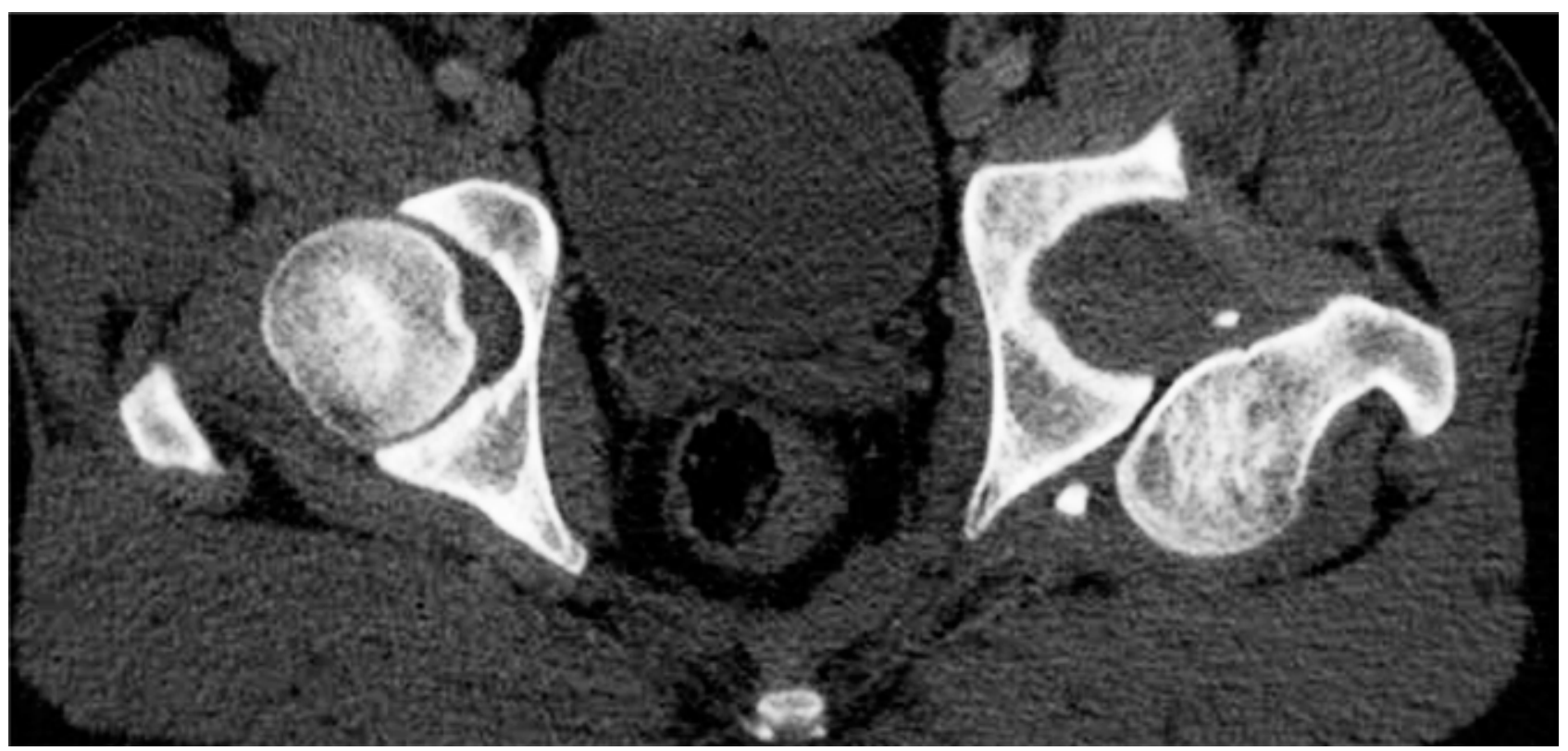

Şekil 2. Çıkık kalçanın BT ile değerlendirilmesi.

grafileri femur başının asetabuluma göre pozisyonunu dolayısıyla çıkığın yönünün tayini sağlayabilir. Judet grafileri overpozisyon nedeniyle gözden kaçabilecek asetabular parçaların tespitini sağlayabilir.

Redükte olmayan çıkıklarda redüksiyon sonrası olası eklem içi kırık parçalarının tespiti ve femur ve/veya asetabulum kırıklarının görülebilmesi için bilgisayarlı tomografi (BT)'den yararlanılmalıdır (Şekil 2). ${ }^{[5]}$

\section{TEDAVi}

Ortopedik acillerden olduğunu bildiğimiz travmatik kalça çıkıklarının, bilindiği üzere osteonekroz riskini en aza indirmek amacıyla en kısa süre içinde redüksiyonu sağlanmalıdır. Genelde acil servislerde sedasyon altında ilk redüksiyonu denenir. İki veya üç denemeden sonra redüksiyon sağlanamadığı takdirde, genel anestezi altında redüksiyon yapılmalıdır. Acil serviste gereğinden fazla zorladığımızda, özellikle osteoporotik hastalarda kırıklara yol açabiliriz. ${ }^{[4,6]}$ ilk saatte gelen hastalarda sedasyon altında redüksiyon başarılı olurken, saatler sonrasında oluşan kas kontraksiyonu redüksiyona engel olacağı için genel anestezi altında kas gevşemesine ihtiyaç olacaktır. Genel anestezi altında kapalı redüksiyon, nadir de olsa başarısız olabilir. Böyle durumlarda açık redüksiyona geçilmesi gerekir. Ayrıca, gecikmiş ve eklem içi kırığı olan çıkıklarda mutlaka açık redüksiyonla başlanmalıdır.
Yukarıda bahsedilen, kalçanın redükte edilememesi durumu \%2-15 oranında görülmektedir. Kalçanın anterior çıkıklarında kapsülün ekleme girmesi, rektus kasının, labrum veya psoasın interpozisyonu buna neden olmaktadır. Daha sık görülen posterior kalça çıkıklarında ise piriformis, gluteus maksimus, kapsül, ligamentum teres, labrum veya kemik parçalar, redüksiyonu engelleyen nedenler olabilir. ${ }^{[4,5]}$

Günümüzde birçok farklı kapalı redüksiyon teknikleri tanımlanmıştır.

\section{Allis Yöntemi}

Supin pozisyondaki hastanın ekstremitesine, diz altından kavranarak uygulayııı tarafından önce olduğu pozisyonda aksiyel traksiyon uygulanır, bir asistan tarafindan pelvis sabitlenip kontraksiyon yapılırken traksiyon altındaki kalça hafif iç rotasyon ve adduksiyonla beraber $70^{\circ}$ 'ye kadar fleksiyona getirilerek ince iç dış rotasyon hareketleri ile arka duvardan atlatılmaya çalışılır. Bu arada bir asistan tarafından femur şaftının proksimalinden yapılacak lateral traksiyon bu atlamayı kolaylaştırabilir. Manevra sırasında duyulabilecek bir "klank" sesi redüksiyonun belirtisidir. Bilinci açık hastada dramatik bir rahatlama görülür.

\section{Stimson'un Yerçekimi Yöntemi}

Pron pozisyondaki hastanın vücudu sedye üzerinde kalçadan itibaren alt ekstremitesi yere sarkacak şekilde 
iken uygulayıcı tarafından baldıra aksiyel traksiyon yapılarak hafif iç-dış rotasyon hareketleri ile redüksiyon sağlanmaya çalışılır. Politravmalı hastalarda olası omurga ve toraks yaralanmaları ekarte edilmeden uygulanmamalıdır.

\section{Bigelow ve Ters Bigelow Yöntemleri}

$\mathrm{Bu}$ tekniklerde redüksiyon mantığı, çıkığın oluş mekanizmasını aynen başlatarak çıkık parçalar arası boşluğun arttırılması ve sonrasında tam tersi manevralarla başın asetabuluma yerleştirilmesi üzerine kuruludur. İyatrojenik kırık riski nedeniyle çok sık başvurulmamaktadır.

Redüksiyon sonrası kalça eklemine en az üç hafta yük verilmemeli, çıkık sonrasında eklemde oluşan yumuşak doku hasarının iyileşmesine fırsat verilmelidir; aksi takdirde instabilite görülme riski artar. Olaya eklem içi kırık eşlik ediyorsa, çıkık taraf iskelet traksiyonu ile en az altı hafta immobilize edilmelidir. Ardından kısmi yük verme ile hareketlere başlanmalıdır. ${ }^{[7]}$

\section{KOMPLIKASYONLAR}

1. Osteonekroz: Redüksiyona kadar geçen süre ile direkt ilişkili olduğunu savunanların çokluğuyla beraber, ilk travma anındaki faktörlerin osteonekroz riskini doğrudan etkilediği de öne sürülmektedir. Bununla beraber, akut dönemde tekrarlayan manevralar gerekmeden redükte edilen kalçalarda geç dönemde osteonekroz görülme sıklığı anlamlı derecede düşük bulunmuştur.

2. Posttravmatik osteoartrit: Kalça çıkığı sonrası uzun dönemde en sık görülen komplikasyondur.

3. Tekrarlayan çıkık: Nadirdir.
4. Damar sinir hasarı: Posterior çıkıklarda siyatik sinirin peroneal dalı en sıklıkla etkilenir. \%40-70'i bir yıl içinde iyileşir, iyileşmeyenlerde cerrahi eksplorasyon gereklidir. Anteriora olan çıııklarda femoral damar sinir yapılarında zedelenme olabilir.

5. Heterotopik ossifikasyon: Açık redüksiyon olgularında daha sık olmakla beraber, profilaktik indometazin kullanılabilir ve radyoterapi uygulanabilir.

6. İyatrojenik femur başı kırıkları.

7. Derin ven trombozu ve tromboemboli: Traksiyonda tutulacak hastalarda kompresif çoraplar ve antiembolik ilaçlar ile profilaksi sağlanmalıdır.

\section{KAYNAKLAR}

1. Al-Bahlool M, Bubshait D, Sadat-Ali M. Outcome of Traumatic Hip Dislocation. Ulus Travma Acil Cerrahi Derg 2009;15(5):463-6.

2. Başal Ö. Alt Ekstremite Kırıkları/Kalça ve Femur. İçinde: Atay T, editör. Ortopedi ve Spor Yaralanmaları Asistan Kitabı. Ankara: Derman Tıbbi Yayıncılık; 2015. s.258-80.

3. Azar N, Yalçınkaya M, Akman YE, Üzümcügil O, Kabukçuoğlu YS. Asimetrik iki Taraflı Travmatik Kalça Çıkığı: Olgu Sunumu. Eklem Hastalık Cerrahisi 2010;21(2):118-21.

4. Obakponovwe, Morell D, Ahmad M, Nunn T, Giannoudis PV. Traumatic Hip Dislocation. Orthop Trauma 2011;25(3):21422. Crossref

5. Tornetta P. Hip dislocations and fractures of the femoral head. In: Bucholz RW, Heckman JD, Court-Brown C, Tornetta P, editors. Rockwood and Green's Fractures in Adults. Philadelphia: Lippincott Williams \& Wilkins; 2006. p.1715-52.

6. Dwyer AJ, John B, Singh SA, Mam MK. Complications after posterior dislocation of the hip. Int Orthop 2006;30(4):2247. Crossref

7. Sanders S, Tejwani N, Egol K. Traumatic Hip Dislocation -a review. Bull NYU Hosp Jt Dis 2010;68(2):91-6. 